This item was submitted to Loughborough's Research Repository by the author.

Items in Figshare are protected by copyright, with all rights reserved, unless otherwise indicated.

\title{
Collection of transport-related data to promote inclusive design door-to-door
}

PLEASE CITE THE PUBLISHED VERSION

https://www.routledge.com/9780415398183/

\section{PUBLISHER}

(c) Taylor \& Francis/Routledge

\section{VERSION}

AM (Accepted Manuscript)

\section{PUBLISHER STATEMENT}

This work is made available according to the conditions of the Creative Commons Attribution-NonCommercialNoDerivatives 4.0 International (CC BY-NC-ND 4.0) licence. Full details of this licence are available at: https://creativecommons.org/licenses/by-nc-nd/4.0/

\section{LICENCE}

CC BY-NC-ND 4.0

\section{REPOSITORY RECORD}

Sims, Ruth, J. Mark Porter, Steve Summerskill, Russell Marshall, Diane E. Gyi, and Keith Case. 2019. "Collection of Transport-related Data to Promote Inclusive Design Door-to-door". figshare. https://hdl.handle.net/2134/26570. 
In P.D. Bust (Ed.), 'Contemporary Ergonomics 2006',

The Proceedings of the Annual Conference of the Ergonomics Society (pp.465-469)

Robinson College, Cambridge, UK, 4-6 April 2006. London: Taylor \& Francis.

Also published in Ergonomics Abstracts, No 211172, 2006.

\title{
COLLECTION OF TRANSPORT-RELATED DATA TO PROMOTE INCLUSIVE DESIGN DOOR-TO-DOOR
}

\author{
Ruth Sims ${ }^{1}$, J. Mark Porter ${ }^{1}$, Steve Summerskill ${ }^{1}$, \\ Russ Marshall ${ }^{1}$, Diane $\mathrm{Gyi}^{2}$, Keith Case ${ }^{3}$ \\ ${ }^{1}$ Department of Design \& Technology, ${ }^{2}$ Department of Human Sciences \\ ${ }^{3}$ Wolfson School of Manufacturing \& Mechanical Engineering \\ Loughborough University, Leicestershire, LE11 3TU
}

\begin{abstract}
A computer-based inclusive design tool (HADRIAN), developed under the EPSRC 'EQUAL' initiative, is being expanded through the EPSRC Sustainable Urban Environments programme. This development will result in the tool including data on transport usage and related issues, providing a database of physical, emotional and cognitive information for 100 individuals, including those who are older and/or physically disabled. The collection of anthropometry by use of body scanning technology, as well as issues concerning the collection of physical capability data, whether by field observation, questionnaire response, or laboratory trials, are discussed. The work detailed is ongoing, and presented here are the methodological and ethical issues arising from consideration of the needs of those wishing to make journeys, and the collection of data to facilitate better design and policy to ease that process. This paper should be read in conjunction with Porter et al (2006) also presented at the conference.
\end{abstract}

\section{Introduction and aims}

The work being conducted will involve data collection from 100 individuals, including those who are older and/or physically disabled. The data collected will consist of anthropometry, joint constraints and reach range volumes, which are used within HADRIAN to construct individual virtual human models of all the participants, and physical task capability data (including postures and behaviours) in kitchen-related bend-reach-lift tasks and transportrelated stepping up/across and reaching tasks. These behavioural elements allow the tool to predict success or failure of virtual tasks for each of the participants. In addition to these data, a questionnaire will also be administered in order to discover some of the cognitive and emotional barriers to travel, as well as coping strategies and further details of physical capability (walking, carrying luggage, climbing stairs, and so on). These data will be entered into the existing HADRIAN software, expanding on data collected previously whenever possible, and additional individuals where this is not possible.

The aim of this paper is to present and discuss some of the methodological issues arising from the aims of the project as a whole, ethical considerations and concerns with using older and/or physically disabled participants, and in obtaining information about the extent of their physical capabilities without putting them at risk of exceeding their capabilities. The future scope of the project will also be presented.

\section{Methodology}

Participant selection

There were a number of issues that arose when the issue of participant selection was considered. It was felt that the complexity of carer interactions would be too difficult at this stage to quantify and model within the software tool. As such the decision was made to 
exclude those who are not physically able to, alone, get themselves out of their house and onto the pavement to join the transport system. Clearly, such people still have needs and aspirations for transport usage, and a future study could exclusively explore the considerations involved with individuals and carers. It was hoped that it would be possible to revisit as many of the 100 people who had previously participated and see if they would be willing to participate again. This would enable some study of the longitudinal aspects of age and disability, due to the number of years since the first study data collection took place. However, some participants might have sadly died in the interim, some might no longer be physically able to get outside without assistance, and some might have changed contact details.

All participants were required to complete a medical screening questionnaire before the trials. However, medical screening questionnaires typically preclude the involvement of people with current medical conditions, yet due to the older and/or disabled nature of many of the participants it was expected that some would have multiple medical complaints, and it is of interest to this work to investigate the problems that these might cause the person when travelling. However, it was required that the experimenters be aware of any conditions that would cause a problem during the course of the trial, so that steps could be taken to reduce the risk and adapt the trials procedure accordingly. As an example, those participants with vertigo/dizziness were not asked to bend low in case this exacerbated the condition.

\section{Questionnaire}

A detailed questionnaire was developed to get rich, detailed information regarding a participant's physical abilities, and also to tap into their cognitive and emotional issues surrounding transport usage. Participants were asked a number of questions concerning their physical abilities, based on the Office of Population Censuses and Surveys scale (1988), transport usage (and reasons for not using, if appropriate) for trains, buses, trams, Londonstyle taxi cabs and minicab taxis, walking distances, as well as issues surrounding taking luggage on the different transport modes (and different amounts of luggage, including suitcases and pushchairs), the types and frequency of journeys made, stairs, lifts, escalators, and timetable usage. The questionnaire also included a request for information about problems experienced in the local area. Any local areas that participants identify as causing problems when travelling will be visited by the experimenters, measurements taken and so on, to verify the reports from the participants. In short, the questionnaire aims to provide information concerning issues that may arise at any point during the whole journey process, from leaving home to wait at a bus stop, walking between transport modes at an interchange, making that change, and arriving at the destination.

\section{Vehicle rig design}

When making a journey using public transport a person might expect to be met with a variety of step heights and handle locations during ingress and egress. A rig was designed to assess participants' ability in these situations, and decisions concerning which heights and handle positions to study were made after referencing the relevant public transport regulations and field observations within the Midlands area. Train carriages and trams are covered by the Rail Vehicle Accessibility (Amendment) Regulations, 2000. This states the maximum step height should be $200 \mathrm{~mm}$, with handrails placed internally on either side of the external doorways, vertically between $700 \mathrm{~mm}$ and $1200 \mathrm{~mm}$ above the floor. From observations it was found that step heights into trains varied between $180 \mathrm{~mm}$ and $280 \mathrm{~mm}$, with the one example of trams having no step at all. London Underground state that the maximum step height on their lines is $240 \mathrm{~mm}$. Buses and coaches (carrying more than 22 people for public usage) are covered by the Public Service Vehicle Accessibility Regulations, 2000. This states that the maximum step height from pavement to bus should be $250 \mathrm{~mm}$, with the first handrail inside the bus being within $100 \mathrm{~mm}$ of the entrance and between $800 \mathrm{~mm}$ and 


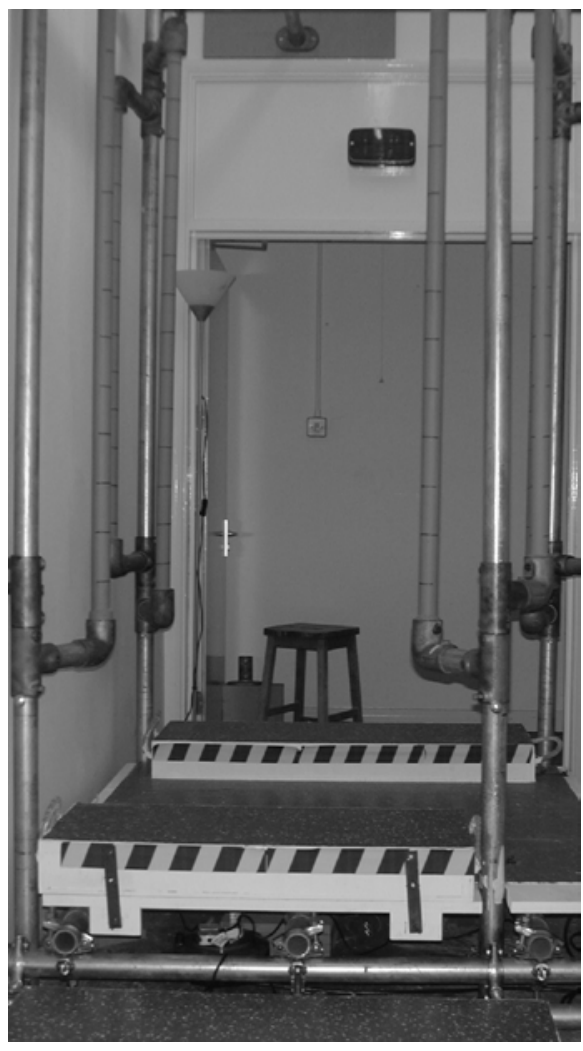

\section{Figure 1. Photograph of the vehicle rig}

$1100 \mathrm{~mm}$ above ground level. Observed step heights for buses were found to vary between $170 \mathrm{~mm}$ and $300 \mathrm{~mm}$, and for coaches between $270 \mathrm{~mm}$ and $370 \mathrm{~mm}$.

A rig consisting of an entrance and exit was designed to reflect these measurements and assess what participants are capable of. This allowed for different 'door' widths on each side: one side narrower to simulate an older-style bus or train, or coach entrance, and the other side wider to simulate the wider access of newer buses and trains. The handles on each side could be placed in a choice of two positions, on the narrow side they could be set at $100 \mathrm{~mm}$ or $200 \mathrm{~mm}$ from the entrance to the 'vehicle', on the wider side they could be set at $300 \mathrm{~mm}$ or $400 \mathrm{~mm}$ from the entrance. The step heights were given as $150 \mathrm{~mm}, 250 \mathrm{~mm}$, or $350 \mathrm{~mm}$ to reflect the worst-case scenario. There was also a $100 \mathrm{~mm}$ gap horizontally between the ground and the 'vehicle' on both sides, to reflect the horizontal gap between pavement/platform and the body of the vehicle.

The design of the rig raised a number of ethical considerations. In order to get a true idea of participants' abilities they would be required to step onto and across the rig. In order to keep the trials as safe as possible a strict protocol was developed and trialled (using ablebodied participants). Participants would complete the questionnaire before attempting the rig, giving information about what the person would attempt and what would cause them problems. The rig was then set up according to these responses: able-bodied participants had both step heights set at the maximum $350 \mathrm{~mm}$, with handles set at $200 \mathrm{~mm}$ and $400 \mathrm{~mm}$ respectively. Less able participants had lower step heights and handle heights adjusted to their ability. Once the rig was set correctly, participants were first asked to observe an 
experimenter demonstrating the task. An experimenter would be standing on each side to offer assistance if required, and it was reinforced that participants should only attempt if they were happy to do so and they should take their time. A rest could be taken if required, and when it came to stepping down participants were asked to first look at the required step and state whether they were happy to continue, before doing so in a controlled, safe manner. Care was taken to reinforce this as participants proceeded with the task. Anyone who felt unsure about the task was obviously free to stop, and steps could be removed if required during the trial.

\section{Body scanner}

The body scanner ([TC $]^{2} \mathrm{NX}_{12}$ Body Measurement System) has the potential to be used to quickly and accurately collect body dimensions, of use in constructing anthropometrically correct virtual human models of individual participants. Participants are required to undress in an enclosed private cubicle into brief clothing that is neutral to their skin tone, as high contrast with skin tone causes problems in attaining a complete scan. To achieve accurate measurements the clothing should fit closely to the body shape. Once inside the scanner itself participants stand and then sit in given postures (demonstrated to them beforehand by the experimenter). Each scan itself takes a matter of seconds, and then the person can exit and dress again. The scan is light-based and therefore harmless, however it was decided to

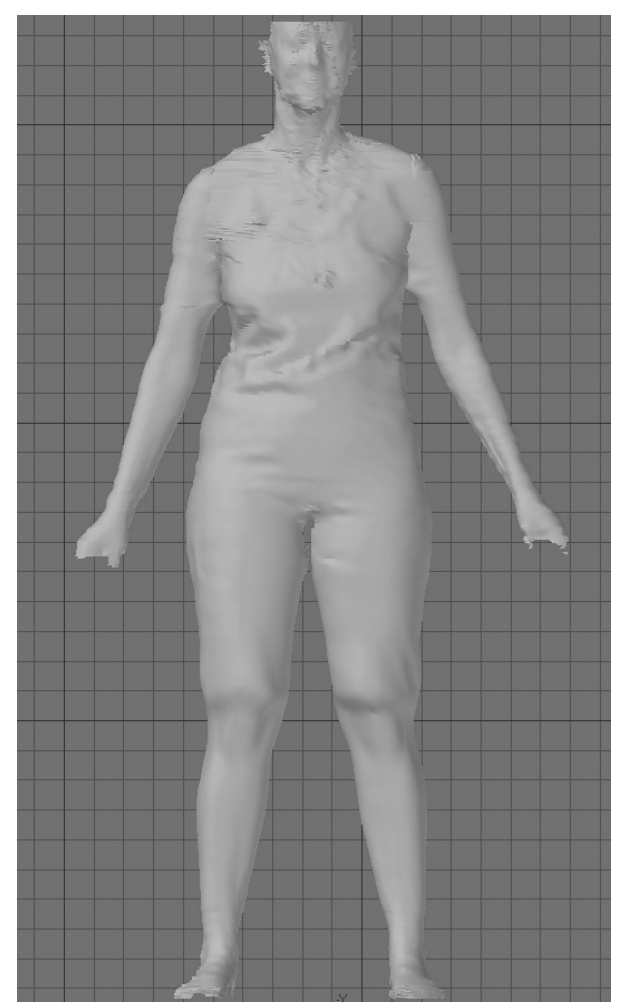

Figure 2. Scanned image 
ask participants prior to the trials if they are epileptic, and any who are will not be required to be scanned.

Traditional external anthropometry was collected to enable comparison with measurements extracted from the scanner to see if the use of the technology made the process quicker and more accurate for able-bodied participants. However, when considering less able participants, they may require assistance to undress and get dressed again (an assistant must be provided by themselves for ethical reasons), and participants may not be willing or able to get undressed/redressed within the scope of the trial. The temperature of the room and how long the process would take them are other issues for concern. Less able participants might also not be able to get into the required positions, and there are issues concerning those in wheelchairs, as the scanner dislikes reflection or high contrast, so a 'stealth' wheelchair would be required for those needing to remain in the chair for the duration.

\section{Future work}

Having completed the lengthy piloting stage of the data collection, and addressed the issues discussed in this paper, it is now expected that the data collection trials will progress in the near future. The data collected will then be entered into the HADRIAN software tool. Future work includes comparison of anthropometry collected using traditional methods versus that obtained from the scanner, to ascertain the accuracy and speed of data collection for different abilities of participants. A separate study of scanning a group of less able participants is also proposed, in order to investigate issues such as the time required and any problems with, for example, parts of a wheelchair obscuring the occupant and the accuracy of the scan, and so on. This in turn will inform future work.

\section{References}

Marshall, R., Porter, J.M., Sims, R.E., Gyi, D.E. and Case, K., 2005 "HADRIAN meets AUNT-SUE" , Proceedings of INCLUDE 2005 , INCLUDE 2005 , Royal College of Art, London, UK, April 2005, pp 1-7, ISBN 1-905000-10-3 , [Also on CD-ROM].

Martin, J., Meltzer, H. \& Elliot, D., 1988, OPCS surveys of disability in Great Britain: The prevalence of disability among adults, (Office of Population Censuses and Surveys, Social Survey Division, HMSO)

Porter, J.M., Marshall, R., Sims, R.E., Gyi, D.E. and Case, K., 2003 "HADRIAN: a human modelling CAD tool to promote "design for all"' , Proceedings of INCLUDE 2003: inclusive design for society and business , 6, Royal College of Art, London , London, 2003, pp 222-228, ISBN 1874175942 , [CD-ROM]

Porter, J.M., Case, K., Marshall, R., Gyi, D.E. and Sims, R.E., 2004, 'Beyond Jack and Jill': designing for individuals using HADRIAN" , International Journal of Industrial Ergonomics , 33, pp 249-264 .

Porter, J.M., Case, K., Marshall, R., Gyi, D.E., \& Sims, R. E., 2006, Developing the HADRIAN inclusive design tool to provide a personal journey planner, Contemporary Ergonomics, Proceedings of the Ergonomics Society Annual conference, 4- $6^{\text {th }}$ April 2006, Cambridge UK

Public Service Vehicles Accessibility Regulations, 2000, Statutory Instrument No.1970 (Department for Transport)

Rail Vehicle Accessibility (Amendment) Regulations, 2000, Statutory Instrument No.3215, (Department for Transport) 